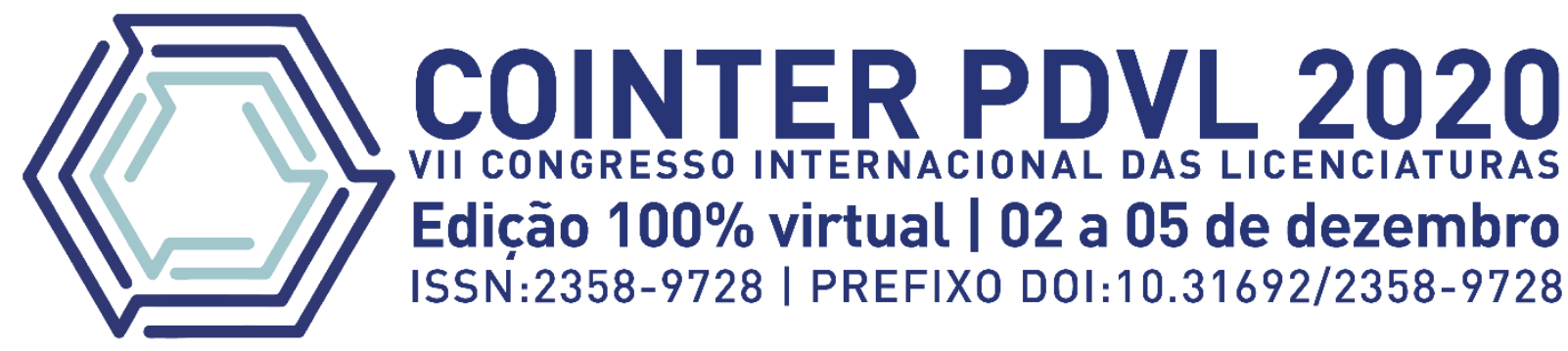

\title{
FATORES CLIMÁTICOS ATUANTES NO SEMIÁRIDO DE PERNAMBUCO: UMA ABORDAGEM DIDÁTICA DA GEOGRAFIA EM SALA DE AULA
}

\author{
FACTORES CLIMÁTICOS QUE ACTÚAN EN EL SEMIÁRIDO DE \\ PERNAMBUCO: UN ENFOQUE DIDÁCTICO DE LA GEOGRAFÍA DEL AULA
}

\section{CLIMATE FACTORS ACTING IN THE PERNAMBUCO SEMI-ARID: A DIDACTIC APPROACH TO CLASSROOM GEOGRAPHY}

\author{
Apresentação: Comunicação Oral \\ João Paulo Angelo Leite ${ }^{1}$; Leonardo Nogueira de Sá2; Gilson Brandão da Rocha Filho ${ }^{3}$
}

DOI: https://doi.org/10.31692/2358-9728.VIICOINTERPDVL.0287

\begin{abstract}
RESUMO
A demarcação do Semiárido Brasileiro foi feita em 1991 pela Empresa Brasileira de Pesquisa Agropecuária (Embrapa), sendo reconhecida cientificamente. O clima semiárido é presente em 88,6\% do estado de Pernambuco sendo bem característico do clima as altas temperaturas devido à grande insolação solar durante todo o ano, e os baixos índices e irregulares de pluviosidade. Vários especialistas argumentam que a seca é oriunda do semiárido e sempre vai existir, por ser característica do clima. Sendo assim o presente trabalho tem como objetivo passar informações científicas acerca das influências climáticas que atuam no semiárido de Pernambuco, abordando seus aportes teóricos e práticos, para alunos do $5^{\circ}$ Ano do Ensino Fundamental da Escola Maria Guilhermina de Jesus, Salgueiro - PE. O mesmo, justifica-se pela importância em trazer aos alunos o conhecimento sobre o clima da região semiárida no qual habitam. Apresentar os conceitos climáticos específicos da área de climatologia, diferenciá-los e aborda-los de forma mais simples e prática, uma vez que os livros didáticos e apostilas adotadas nos sistemas de ensino geralmente apresentam abordagens superficiais sobre o conteúdo de climatologia, muitas vezes não transcendendo os muros escolares. Os conteúdos foram abordados em duas etapas, uma vez por semana, a fim de não causar transtornos aos conteúdos programáticos planejados pelo professor da turma. Foi procurado, sempre respeitar a escolaridade dos estudantes e adequando os conteúdos de climatologia aos mesmos. Sendo de enorme valor que os alunos sejam motivados a compreender e aprender os diversos fatores climáticos existentes no semiárido de Pernambuco essenciais para sua formação escolar.
\end{abstract}

Palavras-Chave: Ensino de Geografia, Clima, Semiárido.

\section{RESUMEN}

La demarcación del Semiárido Brasileño fue realizada en 1991 por la Corporación Brasileña de Investigación Agropecuaria (Embrapa) y fue científicamente reconocida. El clima semiárido está presente en el 88,6\% del estado de Pernambuco, siendo muy característico el clima, las altas temperaturas debido a la gran insolación solar durante todo el año, y los índices de precipitaciones

\footnotetext{
${ }^{1}$ Licenciatura em Geografia, Faculdade de Ciências Humanas do Sertão Central, ipauloangelo1@ @outlook.com

${ }^{2}$ Licenciatura em Geografia, Faculdade de Ciências Humanas do Sertão Central, leo nogueira.sa@ hotmail.com

${ }^{3}$ Geógrafo, Mestre em Gestão Ambiental, Faculdade de Ciências Humanas do Sertão Central, gilsinhogbftf@hotmail.com
} 
escasos e irregulares. Varios expertos sostienen que la sequía proviene de la región semiárida y siempre existirá, ya que es característica del clima. Por tanto, el presente trabajo tiene como objetivo transmitir información científica sobre las influencias climáticas que actúan en la región semiárida de Pernambuco, abordando sus aportes teóricos y prácticos, para los alumnos de $5^{\circ}$ año de la escuela primaria del colegio María Guilhermina de Jesús, Salgueiro - PE. Lo mismo se justifica por la importancia de acercar a los estudiantes el conocimiento sobre el clima de la región semiárida en la que viven. Presentar conceptos climáticos específicos en el área de la climatología, diferenciarlos y abordarlos de una manera más simple y práctica, ya que los libros de texto y folletos adoptados en los sistemas educativos generalmente presentan enfoques superficiales sobre el contenido de la climatología, a menudo no trascendiendo los muros de la escuela. Los contenidos se abordaron en dos etapas, una vez por semana, con el fin de no perturbar el temario planificado por el profesor de la clase. Se buscó respetando siempre la formación de los estudiantes y adaptando los contenidos de climatología a ellos. Es de enorme valor que los estudiantes se sientan motivados para comprender y aprender los diversos factores climáticos que existen en la región semiárida de Pernambuco, los cuales son esenciales para su educación escolar.

Palabras Clave: Enseñanza de Geografía, Clima, Semiárido.

\begin{abstract}
The demarcation of the Brazilian Semi-Arid region was made in 1991 by the Brazilian Agricultural Research Corporation (Embrapa), and was scientifically recognized. The semi-arid climate is present in $88.6 \%$ of the state of Pernambuco, being very characteristic of the climate, the high temperatures due to the great solar insolation throughout the year, and the low and irregular rainfall indexes. Several experts argue that the drought comes from the semiarid region and will always exist, as it is characteristic of the climate. Therefore, the present work aims to pass scientific information about climatic influences that act in the semiarid region of Pernambuco, addressing their theoretical and practical contributions, for students of the 5th year of elementary school at Maria Guilhermina de Jesus School, Salgueiro - PE. The same is justified by the importance of bringing students knowledge about the climate of the semi-arid region in which they live. To present specific climatic concepts in the area of climatology, differentiate them and approach them in a simpler and more practical way, since textbooks and handouts adopted in education systems generally present superficial approaches on the content of climatology, often not transcending school walls. The contents were approached in two stages, once a week, in order not to disturb the syllabus planned by the class teacher. It was sought, always respecting the students' education and adapting the climatology contents to them. It is of enormous value that students are motivated to understand and learn the various climatic factors that exist in the semiarid region of Pernambuco, which are essential for their school education.
\end{abstract}

Keywords: Teaching Geography, Climate, Semiarid.

\title{
INTRODUÇÃO
}

O Semiárido de Pernambuco apresenta temperatura média de $26^{\circ} \mathrm{C}$ e com amplitude térmica que vai desde $24^{\circ} \mathrm{C}$ até os $28^{\circ} \mathrm{C}$, causando baixa umidade na região, o semiárido também sofre com longos períodos de estiagem, com chuvas escassas e mal distribuídas, segundo (NIMER,1979). Com índices pluviométricos de até $800 \mathrm{~mm}$ anual, o que torna o clima quente e seco. Sendo que os índices de evapotranspiração superam, em geral, os totais pluviométricos irregulares da região, ocasionando percentuais negativas no balanço hídrico anual. Segundo informações contidas no Dossiê Nordeste Seco (NORDESTE, 1999).

Conforme (MELO, 1998) O bioma desse clima é a caatinga, com predominância de vegetação xerófila, adaptada aos climas secos. Os índios tupis chamavam a de mata branca em 
alusão à aparência que ela toma quando a água se torna escassa. A caatinga é o único bioma exclusivamente brasileiro e devido a sua herança biológica não pode ser encontrado em nenhum outro lugar do planeta.

Segundo Porto et al. (1983), O período chuvoso ocorre entre os meses de fevereiro a maio. Já a estação seca ocorre entre os meses de agosto a outubro. Nos meses restantes do ano ocorrem poucas precipitações pluviométricas. Segundo a Regulamentação Técnica da OMM número 49 (WMO-No. 49, 1988), O clima é um conjunto de características evidenciadas na atmosfera por um tempo médio ou longo. São observados ao longo das estações do ano em um determinado local, durante um período de aproximadamente 30 anos para puder caracterizar o clima de uma região. Parte da Geografia estuda o clima e a mesma busca entender as variações de temperatura, pluviosidade, vegetação, entre os outros aspectos.

(Moura et al., 2007), Relata que o tempo corresponde ao estado atmosférico em um determinado local de forma momentânea. E por ser um estado temporário significa que dizer que mesmo uma região apresentando clima semiárido, terá dias quentes (frequentemente) e dias frios em um curto espaço de tempo. o tempo está sujeito a diversas variações ao longo das horas.

Além de ser uma região que enfrenta graves problemas relacionados à irregularidade das chuvas, e principalmente as secas severas e prolongadas, como também as chuvas intensas. (Ferreira et al., 2017). O clima do semiárido se configurou no Pernambuco entre 8.000 e 10.000 mil anos atrás e a variação das chuvas é documentado pelos viajantes desde a época do Império. O semiárido Pernambucano é o mais chuvoso do planeta, nele, se precipita, uma variação de 200 a 800mm anuais, já em outros semiáridos do planeta chove entre 80 a 250mm por ano conforme (IRPAA, 2018). De acordo com um estudo de Marengo (2006), "O Semiárido brasileiro sempre foi acometido por grandes secas ou grandes enchentes.” Assim é evidenciado a existência de ciclos de secas e ciclos de maiores precipitações no semiárido pernambucano.

Dessa forma o referente artigo se apresenta com o intuito de proporcionar aos alunos bases sólidas para uma melhor compreensão do clima semiárido de Pernambuco, conceituando o tema para os mesmos de forma clara e objetiva.

\section{FUNDAMENTAÇÃO TEÓRICA}

Cerca de $88,6 \%$ do território Pernambucano fica na parte semiárida assim como mostra a (Figura 01). Dos 184 municípios do estado, 122 estão em áreas sujeitas a desertificação ocasionadas pelas alterações climáticas e pelas ações humanas, de acordo com a Secretaria de Meio Ambiente e Sustentabilidade do Estado (Semas-PE). 


\section{FATORES CLIMÁTICOS ATUANTES NO SEMIÁRIDO DE PERNAMBUCO}

Figura 01: Semiárido de Pernambuco, Brasil.

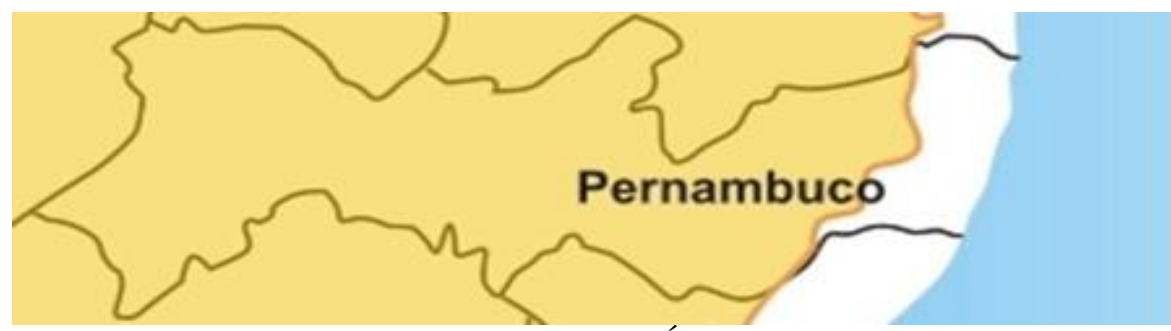

\section{Semiárido}

Fonte: Agência Nacional de Águas(ANA)/Ministério da integração (MI).

O clima semiárido de Pernambuco apresenta altas temperaturas como mostra a (Figura 02), ocasionando uma baixa umidade do ar, além de longos períodos de estiagem. o balanço hídrico da região apresenta deficiência hídrica, porque a evapotranspiração é maior do que as precipitações.

As plantas se adaptaram ao longo de milhões de anos a essa condição climática, ficando em um "modo" de latência nos meses secos, e posteriormente com a chegada das chuvas ficando verdes e frondosas.

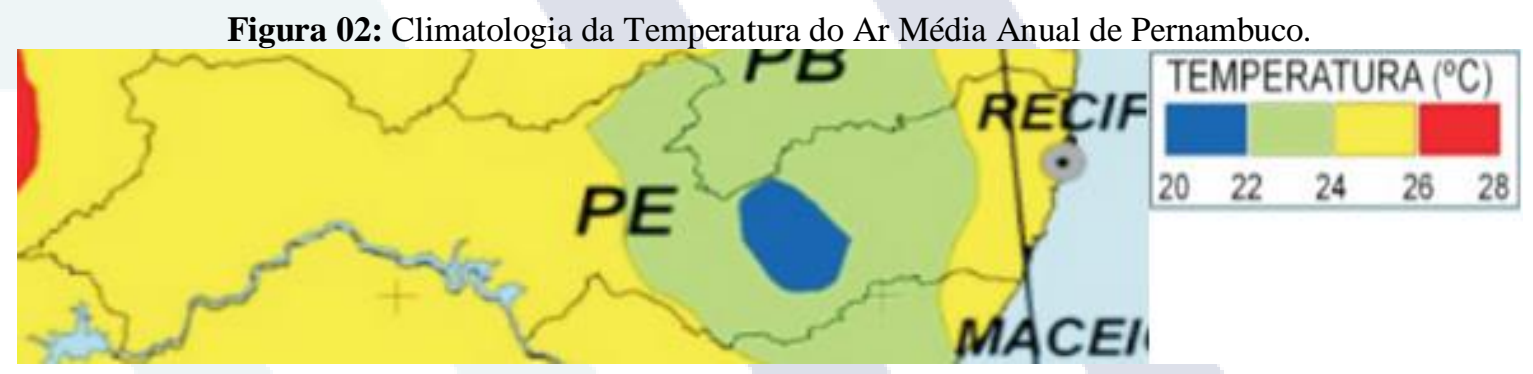

Fonte: Magna Soelma Beserra de Moura e Ivan Ighour Silva Sá, 2010.

O semiárido é o mais quente clima do Brasil com índices pluviométricos de até $800 \mathrm{~mm}$ anual, o tornando quente e seco. Precipitação anual de Pernambuco em (Figura 03).

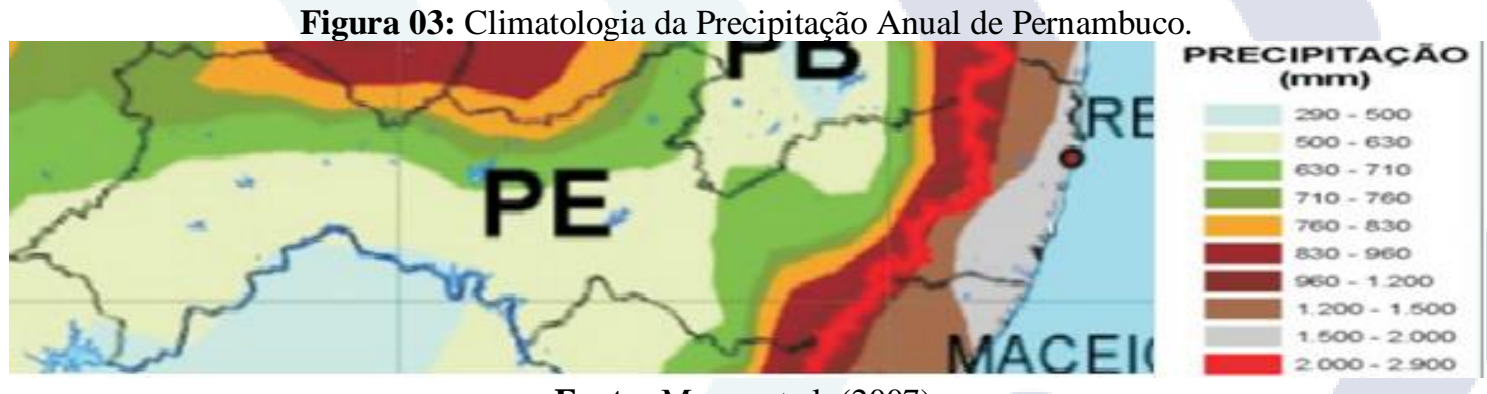

Fonte: Moura et al.,(2007).

As chuvas, por sua vez, concentram-se em três ou quatro meses do ano, não raro dando lugar às enxurradas com trovoadas; essa concentração (máximo de contribuição percentual - MPC) ultrapassa os $50 \%$ do total anual, chegando muitas vezes a aproximadamente $70 \%$ das chuvas do ano (NIMER, 1977).

O período chuvoso no semiárido de Pernambuco ocorre entre os meses do verão no 
hemisfério sul. Assim como é exibido em (Figura 04). Já a estação seca ocorre entre os meses de agosto e outubro. Podemos verificar na figura abaixo os meses do ano conforme o período chuvoso no Semiárido de Pernambuco.

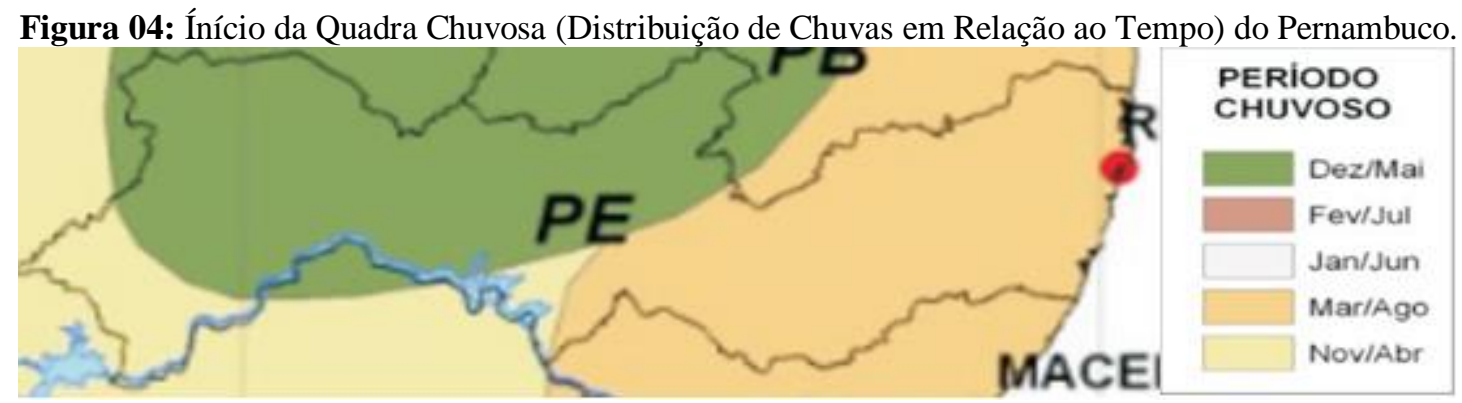

Fonte: Adaptado de Rebouças (1972).

Ropelewski \& Halpert (1987; 1989), Xavier (2001) e Xavier et al. (2003) Entre outros autores, mostraram que os episódios El Niño e La Niña causam impactos sobre a precipitação do semiárido do Nordeste, principalmente na quadra chuvosa (fevereiro, março, abril e maio FMAM). Tanto os sistemas atmosféricos El Niño e La Niña são fortemente atuantes no regime de chuvas e temperaturas no semiárido quando estão ativos no Oceano Pacífico.

(ANDREOLI; KAYANO, 2007), Argumenta que a La Niña é um fenômeno atmosférico de interação do oceano com a atmosfera no qual o oceano apresenta resfriamento abaixo do normal das águas do Oceano Pacífico Equatorial. Assim como mostra a (Figura 05). Com as águas mais frias no Oceano Pacífico, ocorrem grandes mudanças nos padrões normais de ventos e de pressão da circulação geral da atmosfera no planeta Terra, influenciando diretamente o estado de Pernambuco, gerando alterações no padrão climático de chuvas e de temperaturas.

Com a atuação da La Niña as águas mais quentes do Pacífico Equatorial Oeste são represadas ao oeste do Oceano Pacífico pela intensificação dos ventos alísios. Ocasionando uma maior precipitação de chuvas no semiárido pernambucano devido a uma maior descida e atuação da ZCIT na parte norte do Nordeste Brasileiro.

Figura 05: Variação Média da Temperatura da Superfície do Mar (TSM). 


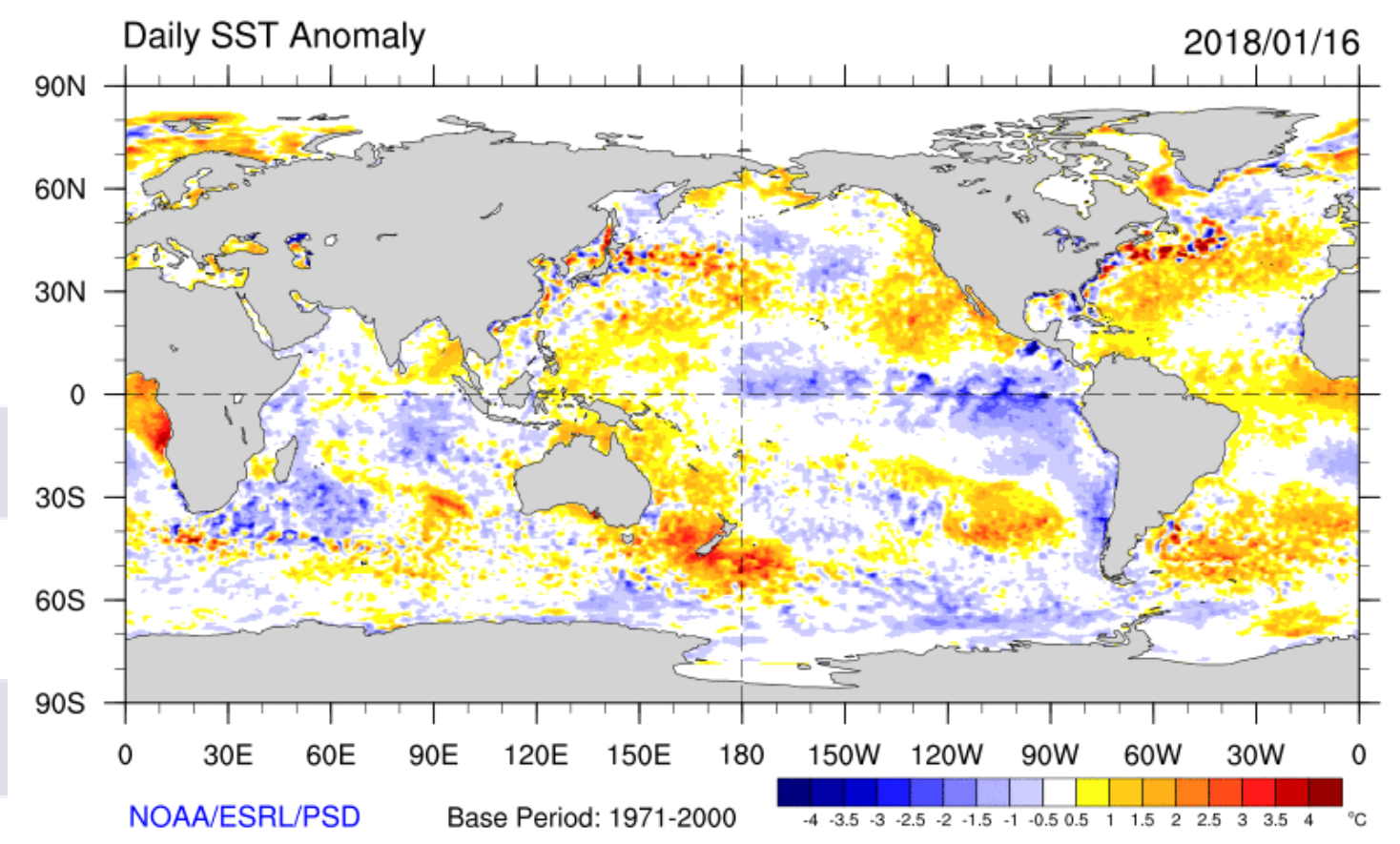

Fonte: NOAA/ESRL/PSD.

(ANDREOLI; KAYANO, 2007), Também menciona o El Niño um fenômeno atmosférico de interação do oceano com a atmosfera no qual o oceano apresenta aquecimento acima do normal das águas do Oceano Pacífico Equatorial assim como mostra a (Figura 06). Com as águas mais quentes no Oceano Pacífico, ocorrem grandes mudanças nos padrões normais de vento e de pressão da circulação geral da atmosfera, essas mudanças geram alterações no padrão climático de chuva e de temperatura em diversas regiões do planeta. Ocasionando uma escassez na precipitação de chuvas no semiárido pernambucano devido a ausência da ZCIT na parte norte do Nordeste Brasileiro.

O El Niño no Pernambuco, age interferindo negativamente na ocorrência de chuvas. Um sistema de alta pressão se forma na região onde o fluxo de ar desce. Este fluxo de ar de cima para baixo é chamado de subsidência e inibe a formação de nuvens e a ocorrência de chuvas. "A ocorrência de veranicos e a própria variabilidade interanual da precipitação são, em muitos casos, decorrentes de fenômenos meteorológicos de grande escala, como o El Niño." (SOUZA et al., 2001).

Figura 06: Variação Média da Temperatura da Superfície do Mar (TSM). 


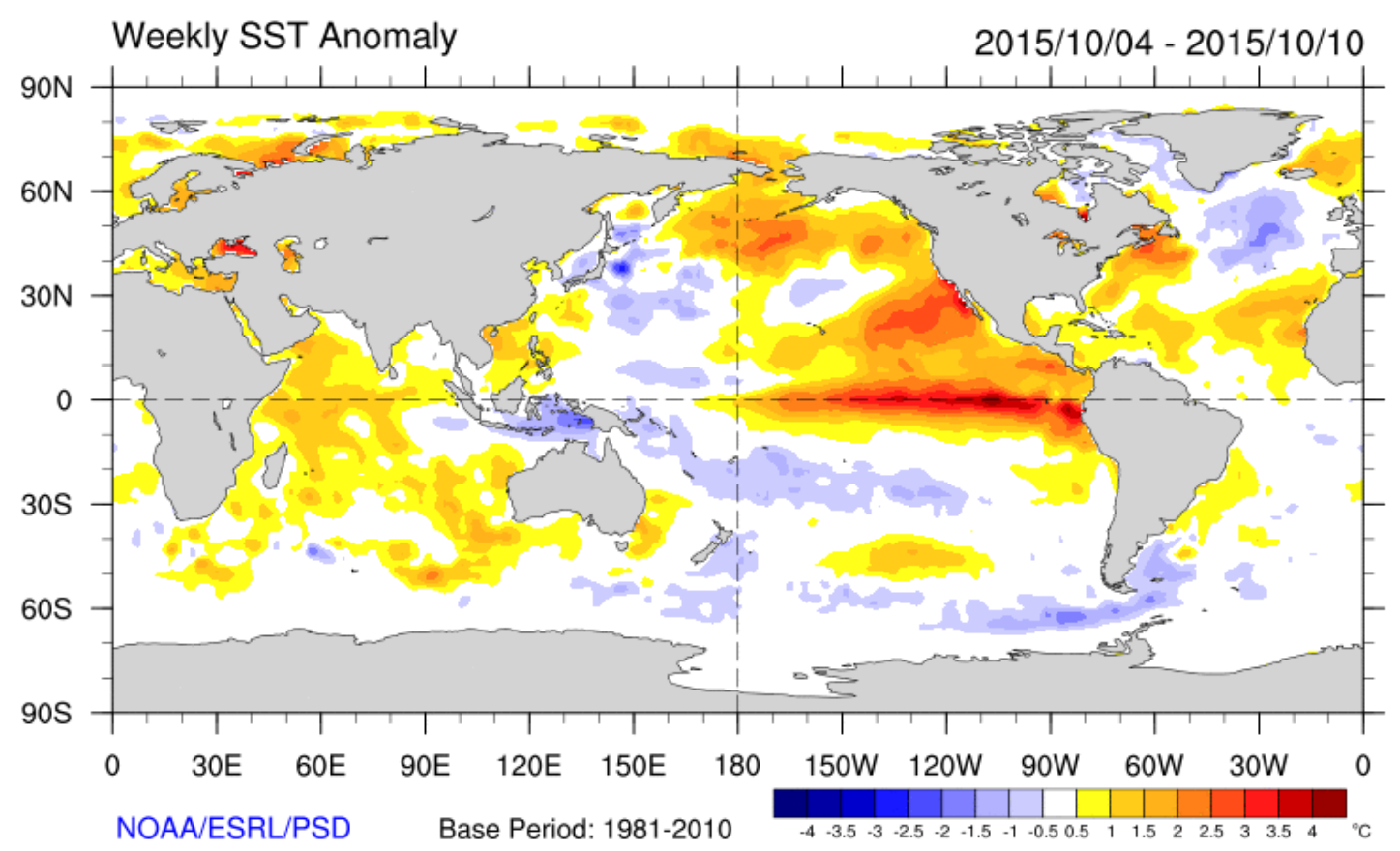

Fonte: NOAA/ESRL/PSD.

(CAVALCANTI et al., 2009), Fala que a Frente Fria é uma área de passagem onde uma massa de ar frio e seca originária do polo se desloca com sentido a linha do equador. De forma inversa acontece com a massa de ar quente no qual ela se desloca para o polo. Assim, ocorrendo trocas de massas de ar. A massa de ar frio é definida como uma coluna de ar que se desloca pela superfície terrestre. Ao encontrar a massa de ar quente o ar frio faz subir o ar quente e o mesmo vai perdendo temperatura a medida que sobe. Raramente uma frente fria chega até o Pernambuco, Regiões de baixas latitudes (próximas a linha do equador), sofrem pouquíssimas interferência de massas de ar vindas dos pólos, muitas massas de ar são desviadas para o oceano devido a sua trajetória.

Quando uma forte massa de ar frio consegue empurrar a massa de ar quente e chegar ao semiárido pernambucano, provoca muita instabilidade gerando fortes rajadas de ventos e grandes volumes de chuvas na região. A partir do momento que essa massa de ar esteja bastante úmida o ar quente começa a condensar e a formar nuvens como por exemplo as cumulonimbus. (Figuras 07-08).

Figura 07: Frente Fria, Carta Sinótica do Brasil.

Figura 08: Nordeste Brasileiro, Precipitação Ocasionada Por uma Frente Fria. 


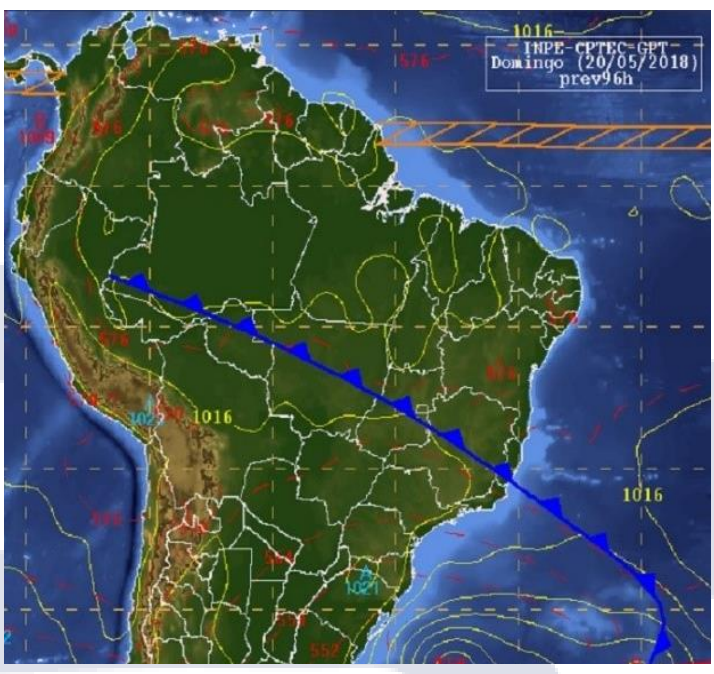

Fonte: INPE-CPTEC-GPT.

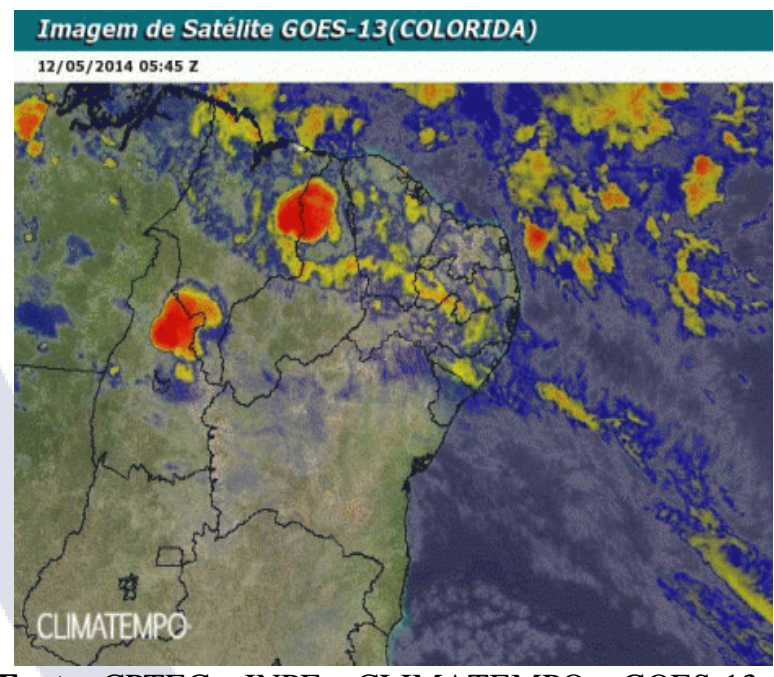

Fonte: CPTEC - INPE - CLIMATEMPO - GOES-13.

(ANDRADE e LINS, 2005), Menciona que a Massa Equatorial Continental (mEc) é uma massa de ar quente e úmido originária da Região Norte do Brasil, e no verão ela se estende por partes do Centro-Oeste e partes do Nordeste incluindo o semiárido de Pernambuco. Sua área de origem é a Amazônia, e por se situa em baixas latitudes e sobre uma grande floresta tropical essa massa de ar se torna úmida e quente. Sendo de grande importância para o transporte da umidade da Floresta Amazônica para o semiárido. (Figuras 09-10).

Figura 09: Mapa do Brasil Mostrando a Atuação da Massa de Ar Equatorial Continental no Verão.

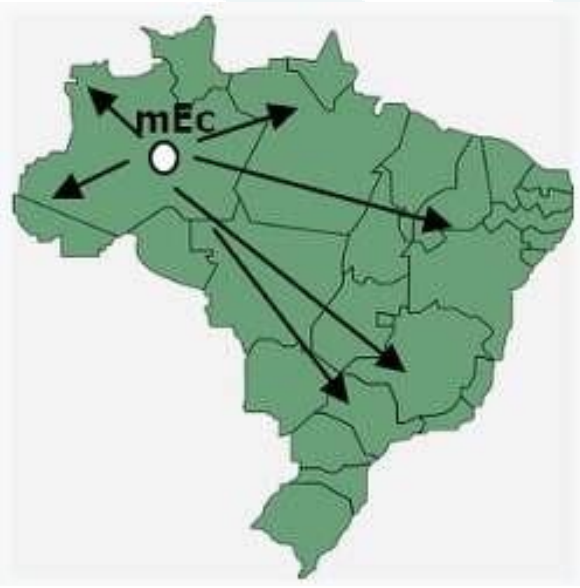

Fonte: www.suapesquisa.com
Figura 10: Mapa de Precipitação Diária do Nordeste Brasileiro, Atuação da Massa de Ar Equatorial Continental no Verão.

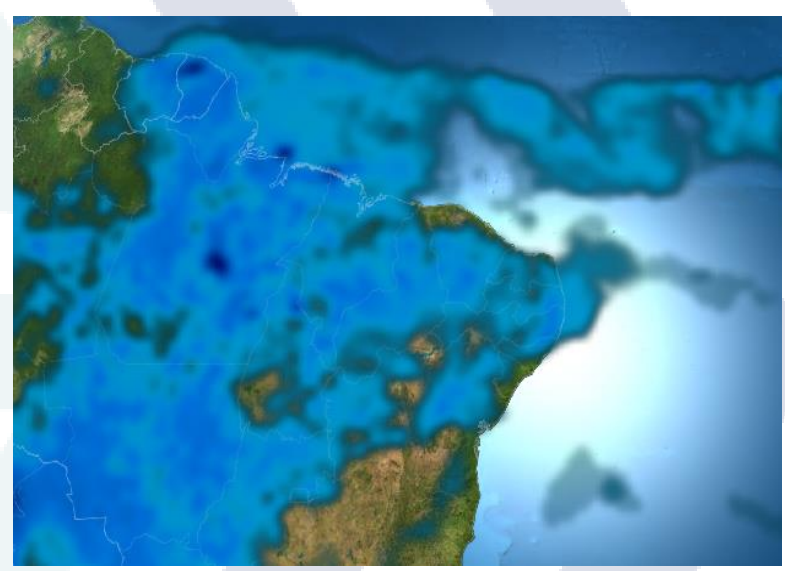

Fonte: MeteoEarth.

(Figueroa et al., 1995; Figueroa, 1997; Gandu \& Silva Dias, 1998). Argumentam que o 
Vórtice Ciclônico de Altos Níveis (VCAN), é um conjunto de nuvens que, ao ser observado pelas imagens de satélite, têm a forma aproximada de um círculo girando no sentido horário fazendo com que o ar seco desses níveis mais altos desça para a superfície.

O VCAN em suas áreas mais centrais, o ar tende-se a ser muito seco impossibilitando a formação de nuvens, consequentemente prejudicando as precipitações. Já nas bordas do vcan a umidade tende-se a ser alta, influênciando diretamente a formação de nuvens de chuvas, sendo muitas vezes do tipo cumulonimbus. O vcan é um sistema atmosférico no qual influência as precipitações no semiárido de Pernambuco, a depender da sua posição na região tanto ocasionará precipitações como estiagens por alguns dias. Observar a (Figura 11).

Figura 11: Vórtice Ciclônico de Altos Níveis (VCAN), Atuando no Nordeste Brasileiro.

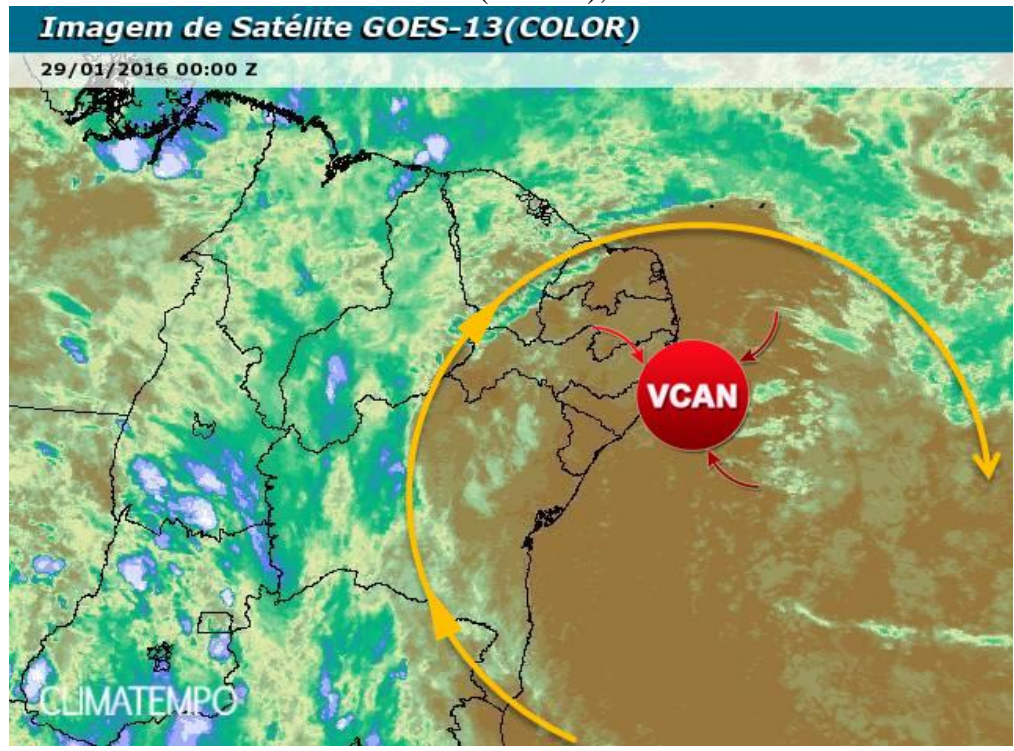

Fonte: CPTEC - INPE - CLIMATEMPO - GOES-13.

(NOBRE; MELO, 2001). Cita que a Zona de Convergência Intertropical (ZCIT) é uma faixa de nuvens que fica ao redor do globo terrestre precisamente na faixa equatorial. A ZCIT surgiu a partir da confluência dos ventos alísios vindos do hemisfério norte com os ventos alísios vindos do hemisfério sul. A partir do encontro desses ventos sobre a Linha do Equador ocorrem altas precipitações pluviométrica devido as altas umidades que são levadas pelos ventos para a região vindas dos oceanos e dos continentes, acarretando a formação de nuvens de chuva nessa faixa equatorial. É um importante sistema de circulação atmosférico no qual definirá o quanto precipitara sobre o semiárido de Pernambuco. Tendo sua variação ocasionada pela temperatura do Oceano Atlântico. Assim como mostra a (Figura 12).

Figura 12: Zona de Convergência Intertropical. 


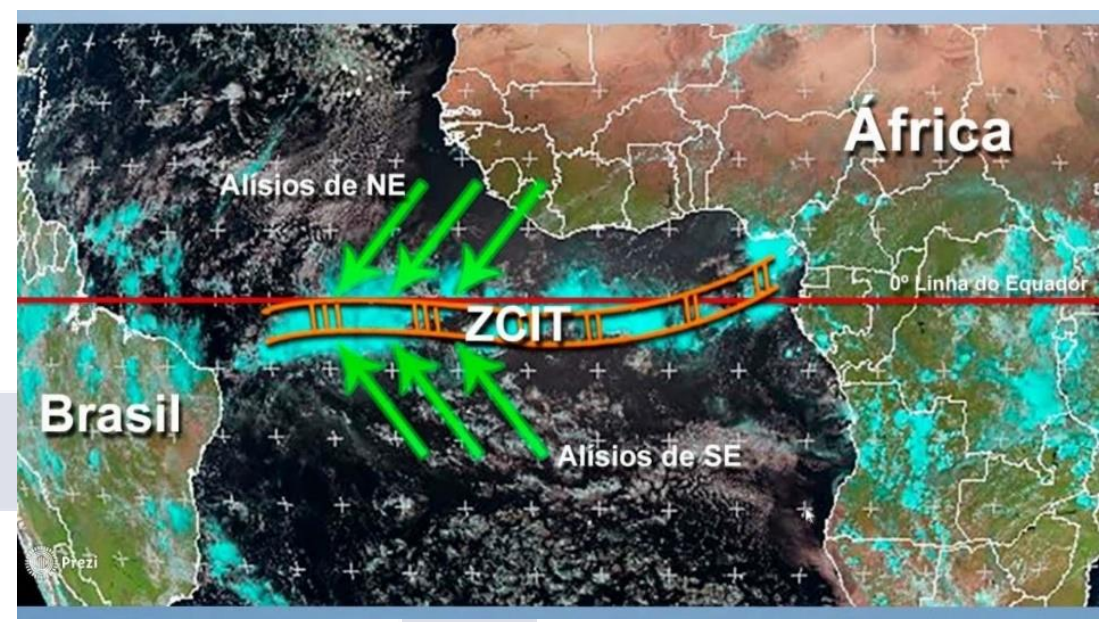

Fonte: EUMETSAT, MET 10.

A ZCIT tem uma maior atuação nos oceanos devido a temperatura da superfície do mar que causa uma maior evaporação das águas para atmosfera, regulando a sua posição e intensidade (CAVALCANTI et al., 2009). Observar a Figura 13 (“A” e "B").

Figura 13: "A": Dipolo do Atlântico positivo (Não Favorável a Chuvas no Nordeste). "B": Dipolo do Atlântico Negativo (Favorável a Chuvas no Nordeste).

(a)

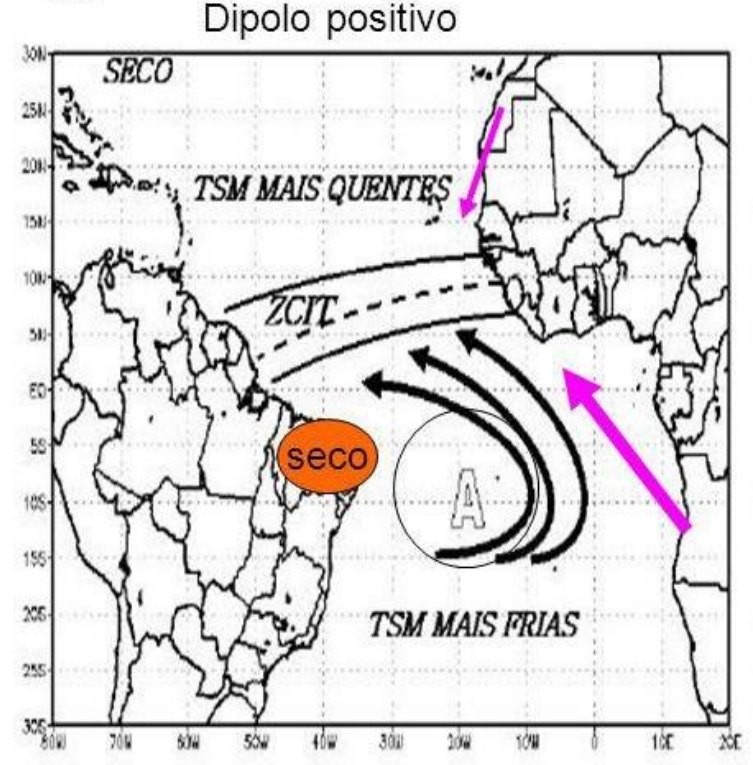

(b)

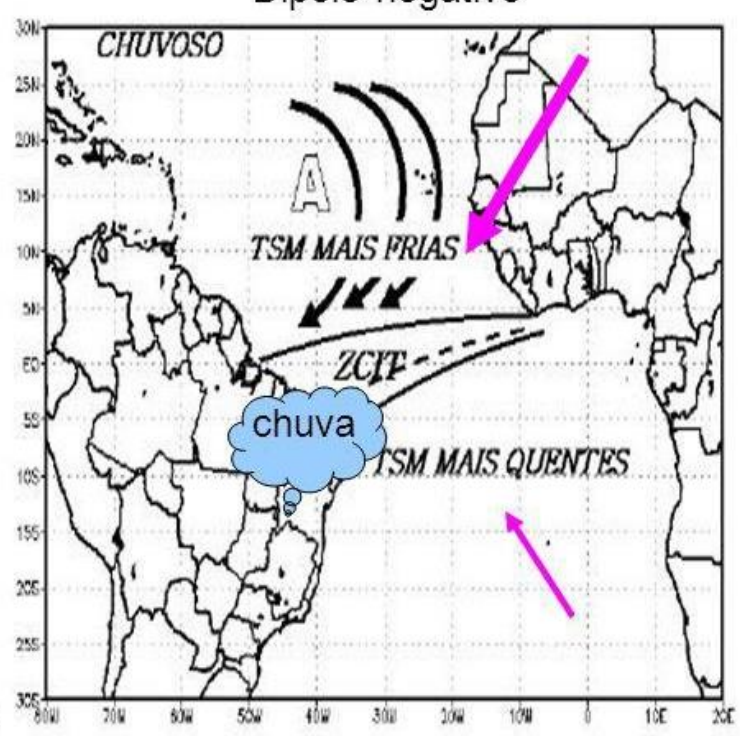

Fonte: INMET.

É possível observar na imagem a baixo que a zona de convergência intertropical (ZCIT) está mais ao sul em relação a linha do equador favorecendo a entrada de umidade no setor norte do Nordeste Brasileiro, consequentemente precipitando-se mais na região semiárida do Pernambuco. (CAVALCANTI et al., 2009). Expõe que isso se dá a um maior aquecimento do 
Oceano Atlântico Sul em relação ao Oceano Atlântico Norte. Ocasionando o deslocamento da ZCIT para águas mais quentes no oceano e favorecendo a ocorrência chuvas nas regiões terrestres próximas ou um pouco mais afastadas em relação a linha do equador. Mapa de precipitação da ZCIT (Figura 14).

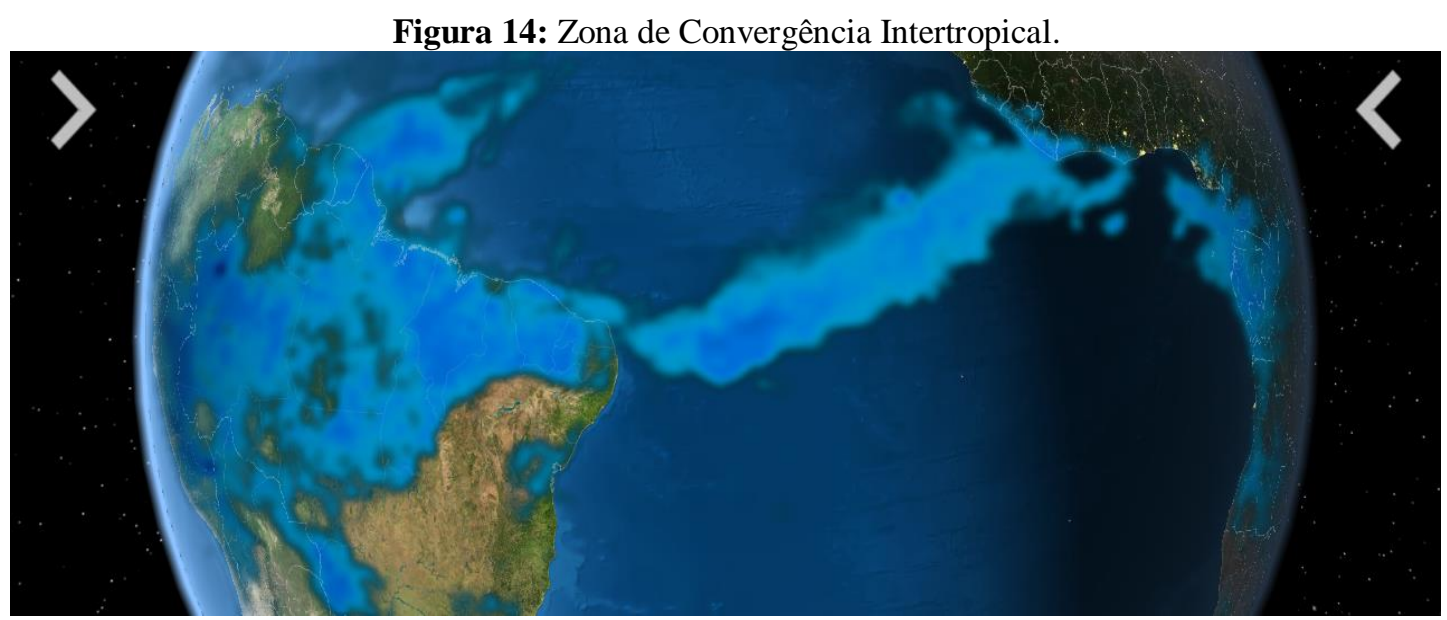

Fonte: MeteoEarth.

A temperatura das águas do Oceano Atlântico Sul tem um papel fundamental na regulação das chuvas sobre o semiárido, ela tem uma enorme relevância para o regime de chuvas na região, se haverá ou não chuvas no semiárido de Pernambuco em um determinado período. "O clima é uma das características mais importantes do Semiárido, principalmente devido à ocorrência das secas estacionais e periódicas” (MENDES, 1997).

Em relação ao semiárido, o mais importante para definir as condições climáticas favoráveis as precipitações na região é que o Atlântico esteja favorável, ou seja, que o Atlântico Sul esteja mais quente que o Atlântico Norte.

O Atlântico Sul mais quente do que o Atlântico Norte beneficia as chuvas como um todo para o semiárido, pôs com o oceano Atlântico Sul mais quente têm-se uma maior descida da ZCIT ocasionando mais chuvas sobre a região. Vale citar que os primeiros estudos mostrando a dependência da precipitação do Semiárido Brasileiro com as anomalias de TSM no Atlântico Tropical foram realizados por Hastenrath \& Heller (1977), Moura \& Shukla (1981) e Silva (2004). Conforme as anomalias de tsm em (Figuras 15-16).

Figura 15: Oceano Atlântico Sul Mais Frio do Que o Normal.
Figura 16: Oceano Atlântico Sul Mais Aquecido do Que o Normal. 


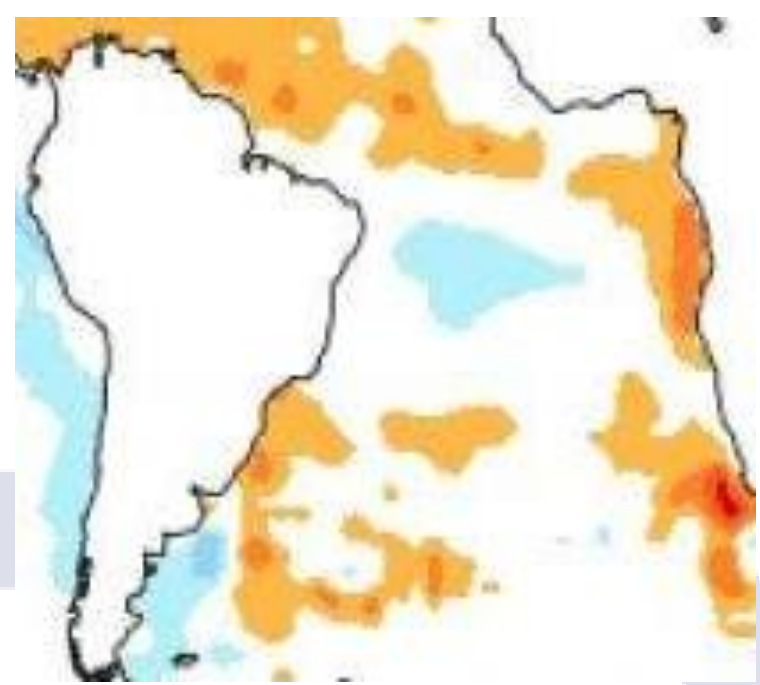

Fonte: CPTEC/INPE.

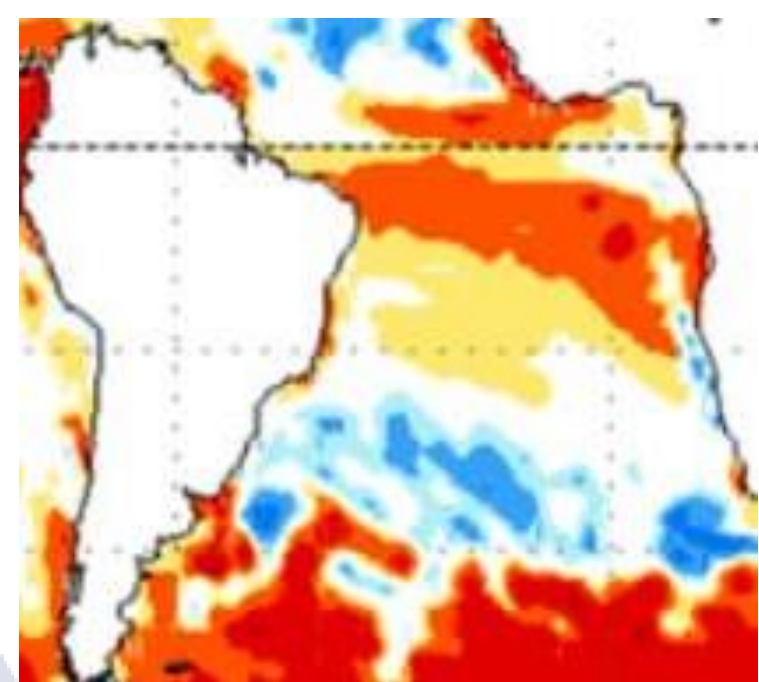

Fonte: NWS, NCEP, CPC.

(CAVALCANTI et al., 2009), Relata que o Planalto da Borborema está situado a leste do Pernambuco, próximo ao Oceano Atlântico. Por causa da sua altitude o planalto interfere na entrada de massas de ar para o interior do estado, trazidas de leste em direção ao semiárido pernambucano. Sendo assim, interferindo no regime de chuvas da região. O interior do Nordeste é separado do oceano por um rebordo anticlinal (sic), a serra da Borborema a leste, e, ao norte por planaltos sedimentares mais baixos. O Nordeste árido fica "debaixo do vento" em relação aos alísios (Damangeot, 1974, p. 34). Conforme a (Figura 17).

Figura 17: Localização do Planalto da Borborema no Nordeste.

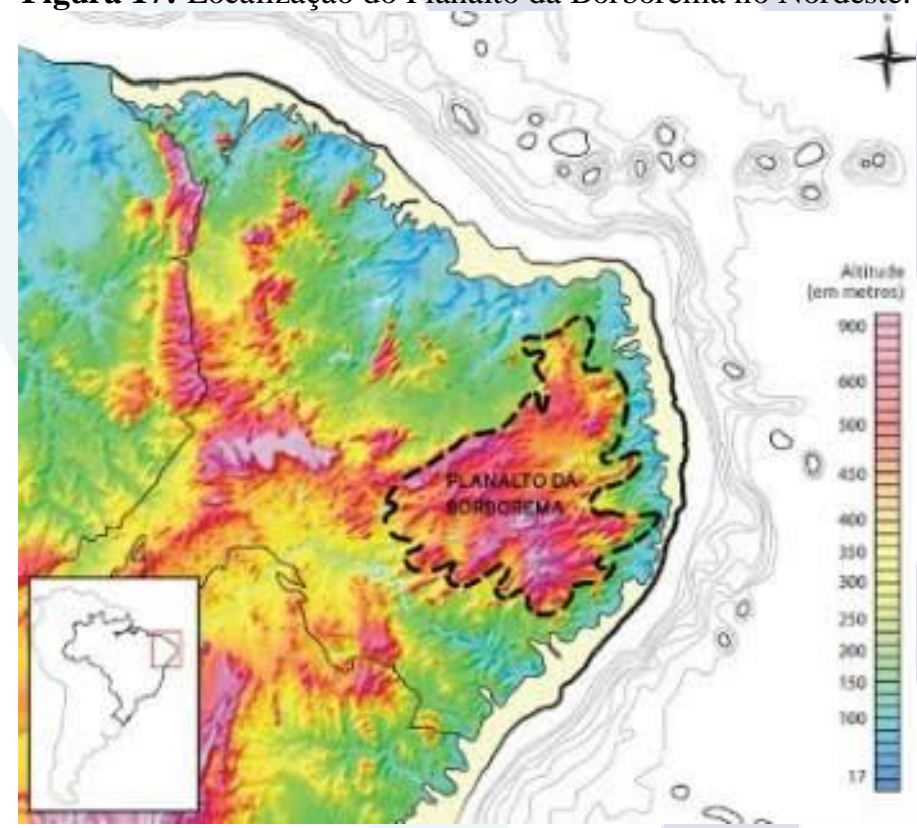

Fonte: www.todamateria.com.br

Assim, pudemos compreender que o planalto gera o impedimento das precipitações no semiárido de Pernambuco, agravando a seca na região e colaborando com a ocorrência do clima 
árido nordestino. (Figura 18).

Figura 18: Representação do Planalto da Borborema e Chuvas Orográficas.

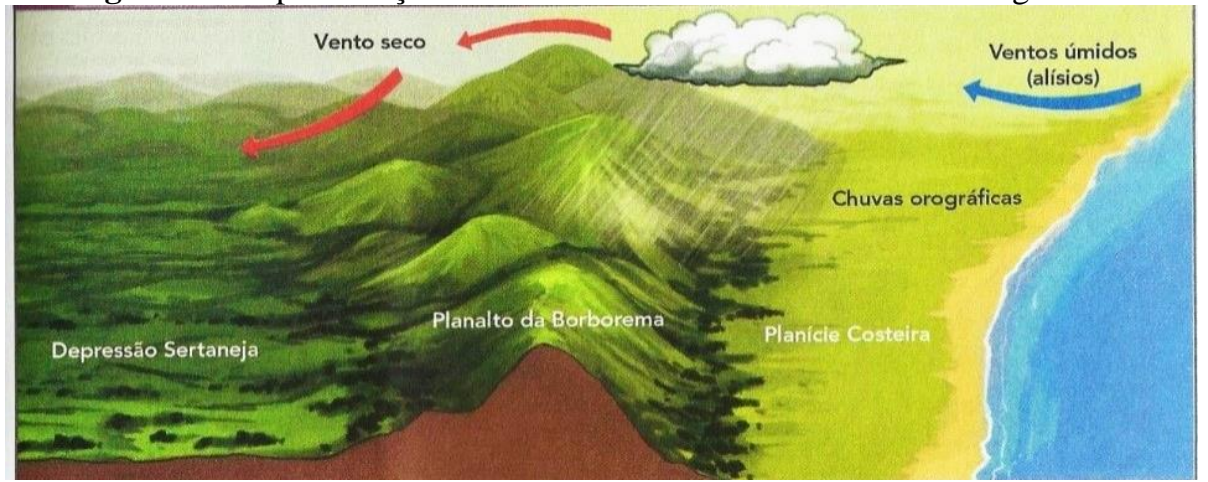

Fonte: Raqsonu, 2011. Digital.

O Planalto da Borborema, acomoda diversos municípios sobre a região, o mesmo tem um comprimento em torno de $400 \mathrm{~km}$ (Norte-Sul). Assim tendo como altitude média de 500 metros e com uma altitude máxima de aproximadamente 1.200 metros. Sendo assim expõe algumas das causas da origem do clima seco no semiárido pernambucano (CAVALCANTI et al., 2009). Assim como é ilustrado na (Figura 19).

Figura 19: Chuva Orográfica

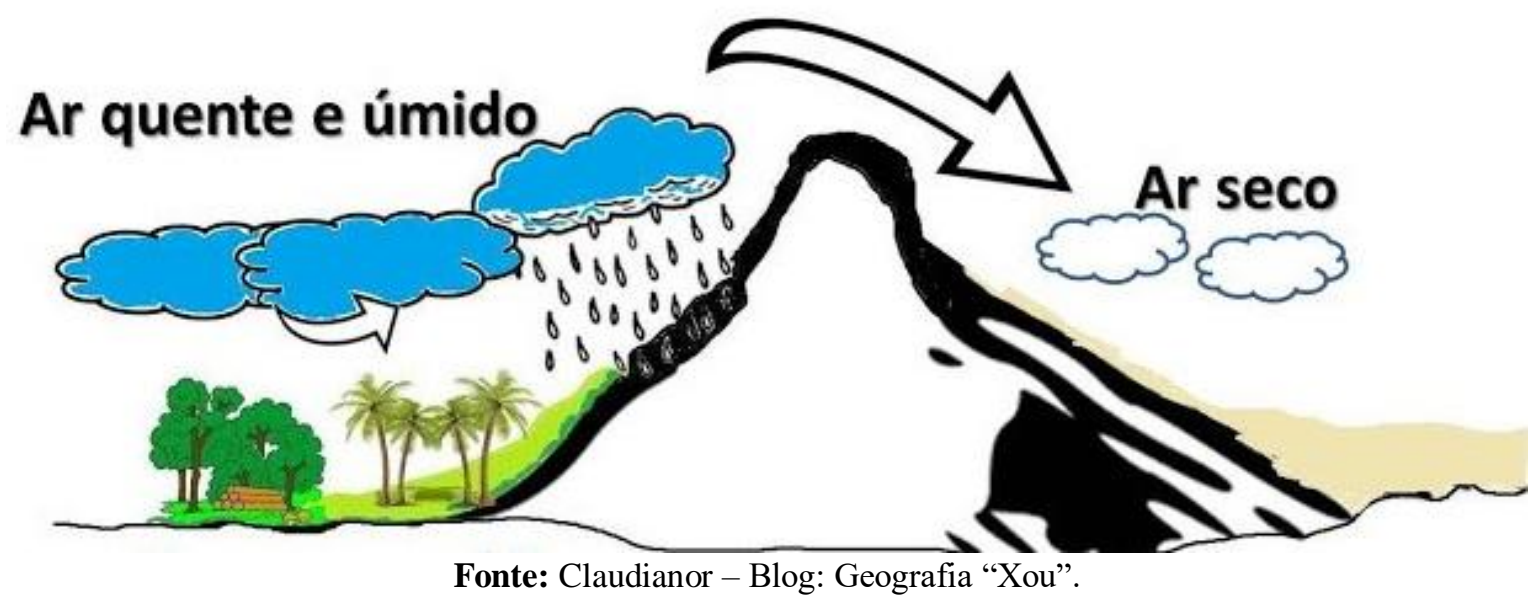

(RAO \& BONATTI, 1987), Argumentam que o Cavado do Nordeste é uma circulação atmosférica que surgi na Bolívia, a mesma age criando uma circulação ciclônica nas altas atitudes da atmosfera, Tendo como a circulação do ciclone no sentido horário. A partir da formação desse anticiclone na Bolívia, é originado um cavado na região do Nordeste do Brasil, acarretando em precipitações no semiárido. Quando se tem tal circulação atmosférica, o mesmo proporciona maiores precipitações por alguns dias durante a sua presença no semiárido pernambucano. Conforme a (Figura 20-21). 
Figura 20: Cavado do Nordeste Ocasionando Mudança na Circulação Atmosférica.

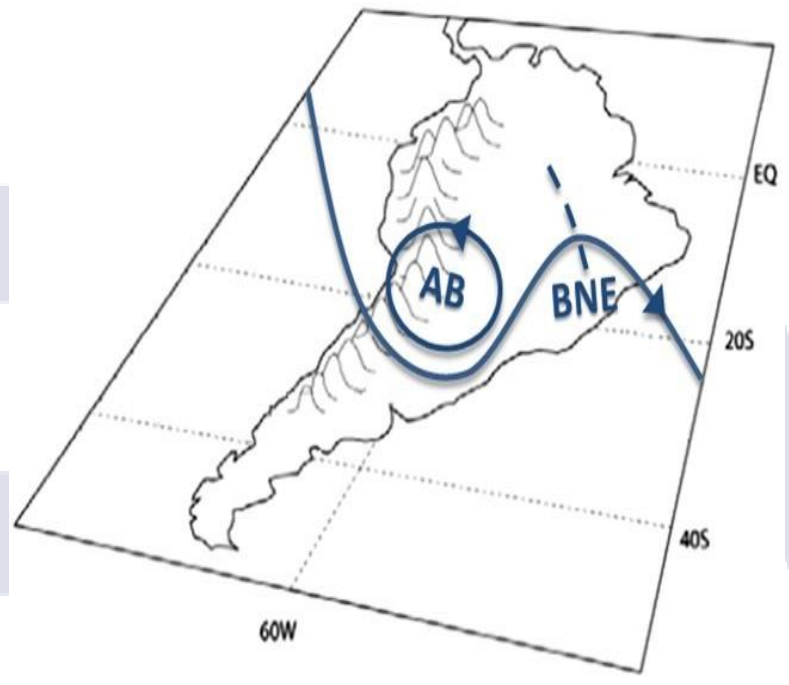

Fonte: letrasambientais.org.br
Figura 21: Cavado do Nordeste Ocasionando Precipitação.

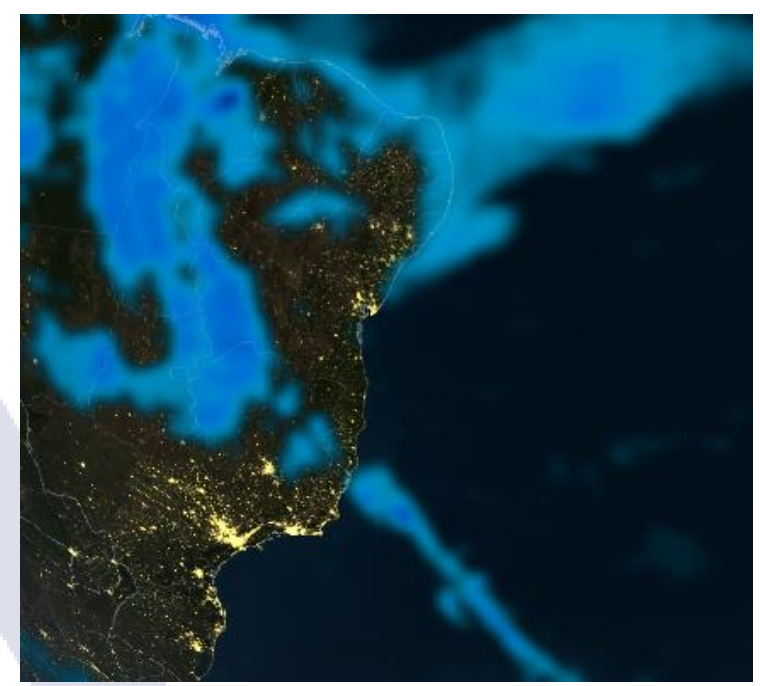

Fonte: MeteoEarth.

O cavado do Nordeste é uma alteração no sentindo dos ventos sobre a Região Nordeste, Deslocando as massas de ar para os baixos níveis da atmosfera na região. Sendo assim levando muitas vezes umidade para o semiárido de Pernambucano. O cavado também varia de posição e intensidade no decorrer dos meses do verão (Rao \& Bonatti, 1987).

\section{METODOLOGIA}

A presente pesquisa tem como natureza qualitativa e exploratória visando uma maior familiaridade com o assunto. Também sendo descritiva buscando descrever os fenômenos, e explicativa para identificar os fatores que determinam ou contribuem para a ocorrência dos fenômenos. A coleta de dados foi feita através de pesquisas bibliográfica. Como fonte de informação conta com pesquisa bibliográfica e campo, já o método de abordagem é indutivo. O campo de pesquisa foi em uma Escola da Rede Municipal, localizada na Cidade de Salgueiro - PE, tendo como sujeitos os discentes do $5^{\circ}$ Ano, onde foi ministrada aulas com o tema fatores e fenômenos climáticos no Semiárido de Pernambuco, com auxílio de Data show e mapas como instrumento de ensino, sendo assim foi possível ter uma "aula expositiva dinâmica", os estudantes ficaram cativados e opinaram sobre o assunto expondo seus conhecimentos. Foi observado e identificado as dúvidas dos estudantes acerca do tema e posteriormente esclarecidos. Em suma, foram ministradas aulas de uma forma simples e fácil para a compreensão, sempre respeitando o grau de instrução dos discentes. 


\section{RESULTADOS E DISCUSSÃO}

De acordo com a (Figura 22) ilustra, uma aula elaborada para a introdução ao tema do clima semiárido de Pernambuco, para o $5^{\circ}$ ano do Ensino Fundamental da Rede Municipal da Cidade de Salgueiro-PE. Diante disso, os alunos tiveram o primeiro contato com o conteúdo sobre Climatologia, conhecendo o clima semiárido a partir fatores e fenômenos climáticos que atuam nessa região, através de uma aula dinâmica, como também perguntas e respostas sobre as principais dúvidas dos alunos em relação ao conteúdo.

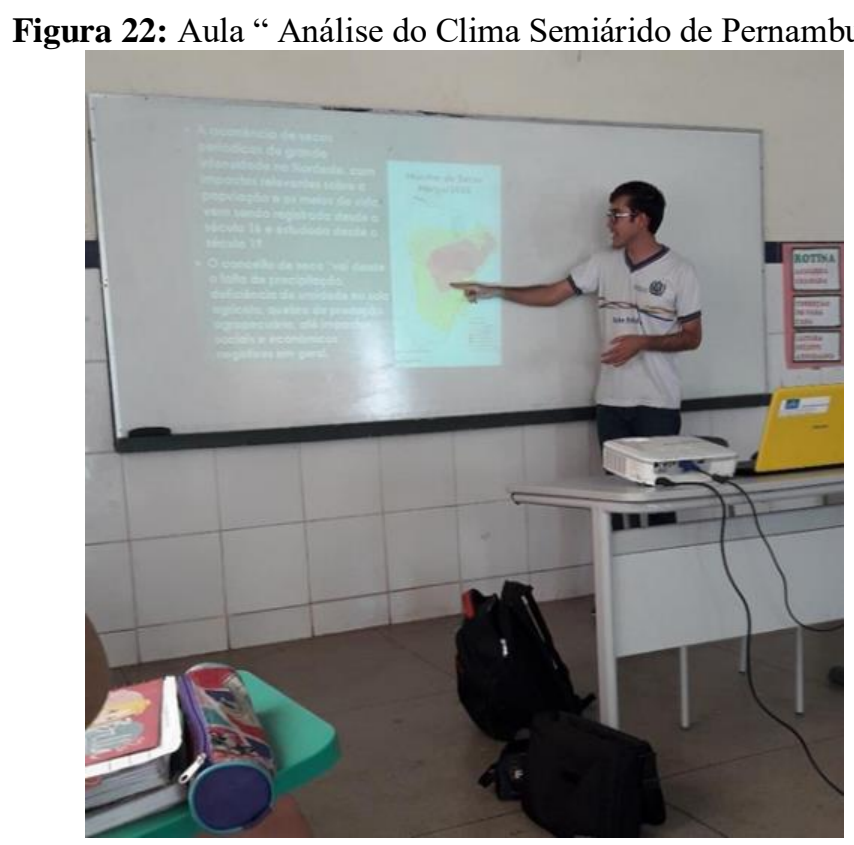

Fonte: Própria (2020).

Castrogiovanni (2007, p. 25) declara que as práticas didáticas devem ser aplicadas de "[...] forma lúdica, inquietante que desperte a curiosidade, envolvendo o sujeito e transformando seu estado intelectual. " Desta forma, a pesquisa teve como intuito proporcionar ao grupo de estudantes bases sólidas para a percepção individual sobre o clima de sua localidade, e que estes tenham uma ferramenta prática para o estudo do clima formas claras e objetivas sobre o porquê do clima de suas regiões serem assim. Como mostra a (figura 23).

Figura 23: "Aula Sobre Fenômenos Atmosféricos". 


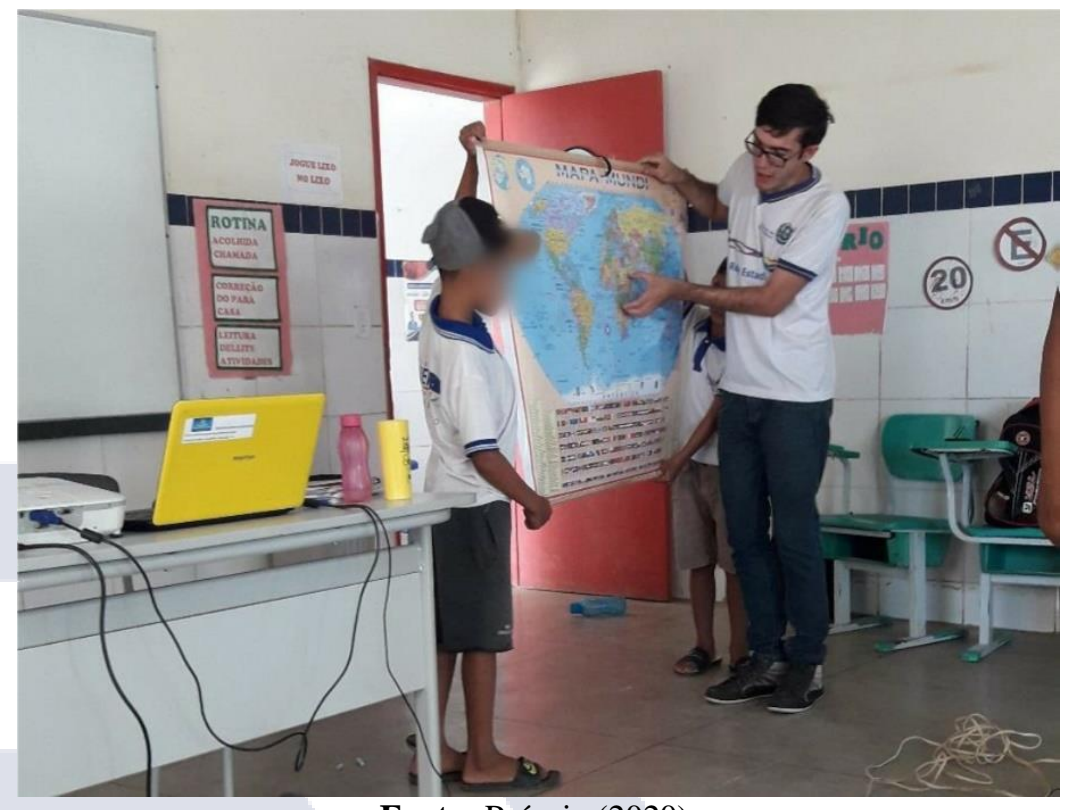

Fonte: Própria (2020).

A renovação do ensino de Geografia, segundo Kaercher (2004) "será alcançada na medida em que o professor tenha uma formação plena, que leve em conta a integração do conhecimento geográfico e pedagógico no ensino escolar. " A aula teve como propósito ensinar aos alunos conceitos e informações sobre o clima semiárido de Pernambuco. Sendo que ao notarmos o interesse dos estudantes pelo assunto abordado em sala, começamos a debater com os mesmo sobre o tema no decorrer dela, como mostra a (figura 24).

Figura 24: Aula Sobre a Importância da Motivação a Participação do Aluno.

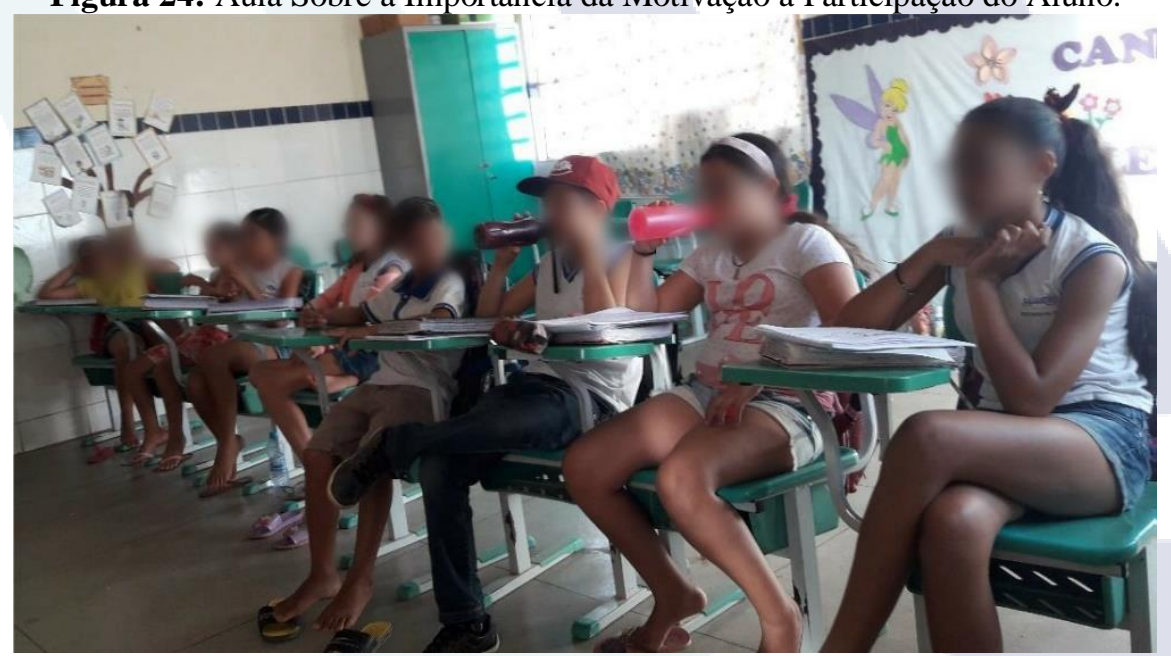

Fonte: Própria (2020).

Para uma maior compreensão da Geografia, segundo Kaercher (2004), pode-se utilizar diferentes linguagens. Por exemplo, a partir do "uso da Literatura, da Pintura, da Música, dos relatos não acadêmicos, de imagens cotidianas, de fala dos populares, etc." O que falta nas escolas, muitas vezes, são esses recursos didáticos. Ou seja, a partir de aulas com auxílio de 
mapas, TVs, aparelhos Data show, vídeos e outros meios, aumenta a probabilidade dos alunos entenderem o espaço geográfico.

A aula se deu de forma satisfatória, fazendo perguntas e sanando dúvidas. Obteve-se respostas relevantes por parte dos alunos em relação ao clima. Ao perguntarmos sobre o porquê de nossa região terem poucas chuvas, alguns souberam definir muito bem. Seguidamente comentaram algumas características do clima semiárido como a vegetação, solos e animais.

Tabela 1: Questionamentos acerca de climatologia.

\begin{tabular}{|c|c|c|}
\hline Perguntas & Definição ( aluno) & Respostas (professor) \\
\hline $\begin{array}{c}\text { Clima e tempo são a mesma } \\
\text { coisa? }\end{array}$ & $\begin{array}{l}\text { O tempo é quando chove } \\
\text { naquele momento. Sobre } \\
\text { o que era o clima, não } \\
\text { souberam responder. }\end{array}$ & $\begin{array}{l}\text { O tempo é o estado físico } \\
\text { das condições atmosférica } \\
\text { em um determinado } \\
\text { momento e local e o clima, } \\
\text { portanto, corresponde ao } \\
\text { comportamento das } \\
\text { condições atmosféricas de } \\
\text { determinado lugar por } \\
\text { muitos anos sucessivos. }\end{array}$ \\
\hline Por que o Nordeste é seco? & $\begin{array}{l}\text { Devidas as poucas } \\
\text { nuvens na região e por } \\
\text { fazer muito calor } \\
\text { resultante da radiação } \\
\text { solar. }\end{array}$ & $\begin{array}{l}\text { Devidas as várias causas } \\
\text { existentes. Por exemplo: O } \\
\text { relevo, posição geográfica, } \\
\text { poucas massas de ar } \\
\text { pressente na região, Etc. }\end{array}$ \\
\hline $\begin{array}{l}\text { Por que a frente fria não } \\
\text { chega aqui no Pernambuco? }\end{array}$ & $\begin{array}{l}\text { Porque fica longe demais } \\
\text { para ela chegar. }\end{array}$ & $\begin{array}{l}\text { Devido as baixas latitudes } \\
\text { da região e as fortes } \\
\text { massas de ar quente } \\
\text { presentes na região. }\end{array}$ \\
\hline $\begin{array}{c}\text { A zcit só ocasionará chuvas } \\
\text { em alguns meses aqui no } \\
\text { Pernambuco? }\end{array}$ & $\begin{array}{l}\text { Vejo falar mais sobre ela } \\
\text { na tv, principalmente nos } \\
\text { primeiros meses do ano. }\end{array}$ & $\begin{array}{l}\text { Sim. A zcit tem uma maior } \\
\text { atuação sobre o } \\
\text { Pernambuco nos meses de } \\
\text { verão. }\end{array}$ \\
\hline
\end{tabular}

Fonte: Própria.

Nesse ambiente discursivo, participaram do desenvolvimento do projeto "fatores climáticos atuantes no semiárido de Pernambuco: uma abordagem didática da geografia em sala de aula" um total de 30 alunos de duas turmas do $5^{\circ}$ ano do ensino Fundamental.

Observando o questionário passado ao final da aula, todos os 30 alunos presentes responderam que foi bom ter o conhecimento acerca do clima semiárido em Pernambuco, além de ficarem interessados em saber mais dos climas atuantes nas outras regiões do Brasil.

Os professores que estavam presentes nas aulas demonstraram interesse na continuação do projeto, que o interesse dos alunos na aula poderia aumentar se possível aplicar esse tipo de aula fora do ambiente escolar, que o aprendizado poderia melhorar, no caso da climatologia. 


\section{CONCLUSÕES}

Constatou-se que as aulas de climatologia no $5^{\circ}$ ano do ensino fundamental podem ser adotadas e devem ser norteadas ao entendimento do cotidiano do estudante, com a compreensão de sua região no espaço terrestre, associando todos os fatores e fenômenos climáticos que interferem no clima e suas características. Assim sendo, pode-se concluir que o ensino de Geografia direcionado a percepção da realidade neste projeto, ampliou o entendimento do clima do semiárido através do conteúdo de climatologia.

Verificando essa ligação com a realidade dos alunos, foi possível observar que o entendimento dos mesmos, quanto ao estudo de clima ainda tem a necessidade de uma maior aplicabilidade do conhecimento do assunto, porém, respeitando o nível de conhecimento e os limites de aprendizagem de cada aluno. Neste caso, é fundamental idealizar novas formas de ensino com incorporação de novos instrumentos didáticos nas escolas, quebrando padrões da educação tradicional, e criando novos métodos educacionais, com o objetivo de alcançar patamares mais elevados do conhecimento e promovendo a socialização abordo do conteúdo de climatologia.

Portanto, a ideia da atividade foi fazer com que os alunos aprendessem e exercitassem os conceitos através dos exemplos do dia a dia, aumentando a interação e a participação coletiva na sala de aula, buscando o entendimento sobre o assunto. O professor, por sua vez, deve observar aqueles estudantes que não compreenderam o assunto e esclarecer novamente para aqueles que erram ou que não participam por não compreenderem, pois isso pode significar o não entendimento dos conceitos de clima. Sendo que ao final das aulas todos possam adquirir um maior conhecimento sobre os fatores climáticos e suas consequências na Região Semiárida de Pernambuco.

\section{REFERÊNCIAS}

ANDREOLI, R. V.; KAYANO, M. T.; GUEDES, R. L.; OYAMA, M. D.; ALVES, M. A. S. A influência da temperatura da superfície do mar dos Oceanos Pacífico e Atlântico na variabilidade de precipitação em Fortaleza. Revista Brasileira de Meteorologia, v. 19, n. 2, p. 337-344, 2004.

CASTROGIOVANNI, A.C. Ensino da geografia: caminhos e encantos. Porto Alegre: EDIPUCRS, 2007.

CAVALCANTI, I. F. A.; FERREIRA, N. J.; SILVA, M. G. A. J. da; DIAS, M. A. F. S. Tempo e clima no Brasil. Oficina de textos, São Paulo, v. 1, 2009. 
DAMANGEOT, J., 1974. O Continente Brasileiro. Difel, São Paulo.

DANTAS, S.P. O Ensino de Climatologia Geográfica: uma abordagem de intervenção sobre os conceitos básico de Clima e Tempo. Revista de Geociências do Nordeste. v. 2, n. Especial, 2016.

FERREIRA, P. dos S; GOMES, V. P.; GALVÍNCIO, J. D.; SANTOS, A. M. dos; SOUZA, W. M. de. Revista Brasileira de Climatologia. Ano 13-Vol. 21-jul/dez, 2017.

HASTENRATH, S., HELLER, L. Dynamics of climatic hazards in north-east Brazil. Quartely Journal of the Royal Meteorological Society, v. 110, p. 411-425, 1977.

INSTITUTO REGIONAL DA PEQUENA AGROPECUÁRIA APROPRIADA. Seca no Semiárido? Disponível em http://www.irpaa.org/publicacoes/artigos/seca-nosemiarido.pdf. Acesso em: 10.out.2020.

KAERCHER, N. A. A geografia escolar na prática docente: a utopia e os obstáculos epistemológicos da Geografia Crítica. São Paulo. 2004. 363f. Tese (Doutorado em Geografia Física) - Faculdade de Filosofia, Letras e Ciências Humanas, Universidade de São Paulo, São Paulo, 2004.

MARENGO, J. A. Mudanças climáticas globais e seus efeitos sobre a biodiversidade: caracterização do clima atual e definição das alterações climáticas para o território brasileiro ao longo do século XXI. Brasília, DF: MMA, 2006. 202 p. il. (Biodiversidade, 26).

MELO, A. S. Tavares de. Desertificação: etimologia, conceitos, causas e indicadores, Rev. do UNIPÊ, João Pessoa: UNIPÊ, 2 (2):21-35, 1998.

MENDES, B. V. Biodiversidade e desenvolvimento sustentável do Semiárido. Fortaleza: SEMACE, 1997. 108 p. il.

MOURA, A. D., SHUKLA, J. On the dynamics of the droughts in Northeast Brazil: observations, theory and numerical experiments with a general circulation model. Journal Atmospheric Science, v. 38, n. 12, p. 2653-2673, 1981.

MOURA, M. S. B. et al. Clima e água de chuva no Semiárido. In: BRITO, L. T. de L.; MOURA, M. S. B. de; GAMA, G. F. B. (Ed.). Potencialidades da água de chuva no Semiárido brasileiro. Petrolina: Embrapa Semiárido, 2007.

NIMER, E. Clima. In: Geografia do Brasil: Região Nordeste. Rio de Janeiro: IBGE, v. 2, 1977. pp. 47-84.

NIMER, Edmon. Pluviometria e recursos hídricos de Pernambuco e Paraíba. Rio de Janeiro: IBGE, 1979. 128 p. il. (recursos naturais e meio ambiente, 3).

NORDESTE sertanejo: a região semi-árida mais povoada do mundo. Estudos Avançados, São Paulo, v. 13, n. 35 p.60-68, Mai/Ago. 1999.

PORTO, E. R.; GARAGORRY, F. L.; SILVA, A. de S.; MOITA, A. W. Risco climático: estimativa de sucesso da agricultura dependente de chuva para diferentes épocas de 
plantio I. Cultivo do feijão (Phaseolus vul - garis L.). Petrolina, PE: EMBRAPA-CPATSA, 1983. 129 p. (EMBRAPACPATSA Documentos, 23).

Rao, V. B.; Bonatti, J. P. On the origin of the upper-tropospheric cyclonic vortices in the South Atlantic Ocean and adjoining Brazil during summer. Meteorological Atmosphere Physics, v.37, p.11-16., 1987.

Ropelewski, C. F.; Halpert, M. S. Global and regional scale precipitation patterns associated with the El-Nino Southern Oscillation. Monthly Weather Review, v.115, p.16061626, 1987.

Ropelewski, C. F.; Halpert, M. S. Precipitation patterns associated with the high index phase of the southern oscillation. Journal of Climate, v. 2, p. 268-284, 1989.

SILVA, V. P. R. On climate variability in Northeast of Brazil. Journal of Arid Environments, v. 58, p. 575-596, 2004.

SOUSA, S. S.; TOMASELLA, J.; GARCIA, M. G.; AMORIM, M. C.; MENEZES, P. C. P.; PINTO, C. A. M. O Programa de Monitoramento Climático em Tempo Real na área de atuação da SUDENE - PROCLIMA. Boletim da Sociedade Brasileira de Meteorologia, São José dos Campos, v. 25, n. 1, p. 15-24, 2001.

STEINKE, E.T. Prática Pedagógica em climatologia no ensino fundamental: sensações e representações do cotidiano. ACTA Geográfica, Ed. Esp. Climatologia Geográfica, p. 77-86, 2012.

World Meteorology Organization $n^{\mathbf{o}}$ 49. Technical Regulations: General Meteorological Standards and Recommended Practices. Vol. 1, Secretariat of the World Meteorological Organization. Geneva, 1988.

Xavier, A. F. S.; Silva-Dias, M. A. F.; Silva-Dias, P. L. Interrelações entre Eventos ENOS (ENSO), a ZCIT (ITCZ) no Atlântico e a Chuva nas Bacias Hidrográficas do Ceará, Revista Brasileira Recursos Hídricos, v. 8, n. 2, p. 111-126. 2003. 